\title{
Roasting optimization and kinetics of raw and instant controlled pressure drop pre-treated coffee beans
}

Optimización de tostado y cinética de granos de café pretratados con caída de presión cruda e instantánea
Author:

Kamal I ${ }^{1}$

Allaf $\mathbf{K}^{2}$

\section{SCIENTIFIC RESEARCH}

How to cite this paper:

Kamal I., Allaf K.. Roasting optimization and kinetics of raw and instant controlled pressure drop pre-treated coffee beans. Innovaciencia. 2019; 7 (1): 1-16.

http://dx.doi.org/10.15649/2346075X.511

Reception date:

Received: 25 February 2019

Accepted: 30 April 2019

Published: 25 October 2019

Keywords:

Coffee; Instant Controlled Pressure Drop

Process (DIC); Coffee roasting kinetics; Degree of roasting; Scanning Electron Microscopy (SEM); Response Surface Methodology (RSM).

\section{ABSTRACT}

Introduction: Coffee is one of the most widely consumed beverages in the world. The desired aroma and flavour of coffee are developed during roasting which is the most important step in coffee processing. Instant Controlled Pressure Drop Process (DIC) technology is controlled high temperature and short time process which been used successfully to improving the kinetics of drying, extraction, and decontamination of fresh and dried natural products. The main advantages of DIC are that it is a master controlled temperature and time process, the dwell times are short, reducing the chemical degradation, so new products with superior quality attributes may be developed. Materials and Methods: Two coffee beans varieties were investigated by Brazilian and Ethiopian sources. The raw beans were pre-treated using the DIC process under adopted conditions prior to roasting. A two-factor central composite design was used to optimize the settings of roasting time and roasting temperature on response variables of bulk, true and normalized density, and roasting degree. Also, microscopic analysis using Scanning Electron Microscopy (SEM) and kinetics of the roasting processes are included. Results and Discussion: The obtained results confirmed that the roasted DIC treated beans for both varieties have lower densities, higher roasting degree and lower activation energy needed for roasting compared to the raw beans. The physical properties' magnitude is highly relevant to coffee origin. Roasting time and the temperature seemed to be of significant regarding all the physical characteristics of the beans, however, time was of topmost significance. Besides, treating coffee been by DIC prior to roasting leads to texture modification and conservation of time and energy needed for roasting. Conclusions: The physical properties of the roasted coffee beans are highly affected and changed with the coffee origin, roasting conditions and pre-treatment of coffee beans prior to roasting using the DIC process. The incorporation of the DIC process prior to roasting seemed to achieve more conservation of time and energy needed for roasting compared to the raw untreated beans. The higher degree of roasting and the competitive roasting activation energy of Brazilian coffee beans give a conclusion that more economic roasting process could be achieved with the Brazilian coffee. The pre-treatment by DIC enhances the remarkable reduction in coffee beans density and increasing in the roasting degrees that are in line with the industrial needs of coffee beverages. Response Surface Methodology is an efficient tool for optimization and mathematical modeling of the coffee roasting process.

1 Chemical Engineering Department, Faculty of Engineering, Soran University-Kurdistan Region, Iraq, ibtisam.kamal@soran. edu.iq,

2 University of La Rochelle, Laboratory of Sciences and Engineering for the Environment, LaSIE FRE-CNRS 3474 / France, kallaf@univ-lr.fr, 


\section{INTRODUCTION}

Coffee is one of the most widely consumed beverages in the world. The desired aroma and flavor of coffee used for beverage are developed during roasting which is the most important step in coffee processing, causing marked chemical, physical, structural,

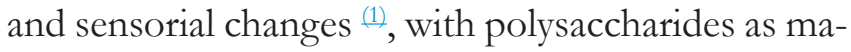
jor factors in the changing physicochemical profile of the coffee bean during processing $\stackrel{(2)}{-}$. Hundreds of chemical reactions take place simultaneously during roasting ${ }^{(3)}$. The chemical reactions occurring are known as Maillard reactions and Strecker degradation reactions $\stackrel{(4)}{{ }^{2}}$, the result of which is a complex mixture of organoleptic compounds that are responsible for aroma and taste of coffee $\frac{(5)}{\text {. }}$.

The roasting process can be divided into three consecutive stages: (a) drying, (b) pyrolysis, (c) cooling (6). The first stage of roasting is endothermic where water and volatile substances are slowly released, bean color changes from green to yellow and beans begin to smell like toast or popcorn. Pyrolysis reactions take place after that resulting the breaking down of complex polysaccharides into starches and then sugars, which caramelize. Larger quantities of $\mathrm{CO}_{2}$ and $\mathrm{H}_{2} \mathrm{O}$ and volatile compounds are released. Aromatic oils within the beans boil to the surface, giving them an oily appearance. Along the way the beans darken to a rich chestnut brown due the sugar caramelization coupled to Maillard reaction. At this point cooling is required in order to avoid burning the beans. The longer the beans are roasted, the darker they become and the more apparent the flavor. Darker roasts have a tendency to be less acidic because of the structural breakdown. They also have less caffeine then the lighter roasts. Furthermore, extracts of coffee beans at the maximum degree of roasting were found to be the most potent inhibitor of some chronic degenerative diseases and various human cancers $\frac{(7)}{7}$.

Roasting conditions can vary greatly, depending on variety, age, moisture content of coffee beans, type of roaster, and also on the degree of roasting required $\stackrel{(6)}{-}$. The degree of roasting can be monitored by the developed flavor of aroma, by the color of the beans, by the chemical changes of certain com-

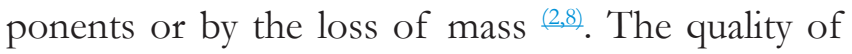
coffee used for beverage is related to the chemical composition of the roasted beans, which, in turn, is affected by the chemical composition of the green beans and by post-harvesting processing ${ }^{(9)}$. Grinding conditions is also affected the quality of coffee beverage $\stackrel{(10)}{ }$.

Physical properties of biological materials are important in the design of the handling system, in grading and in hulling of the materials $\stackrel{(11)}{ }$. Bulk density influences the efficiency of coffee extraction during brewing, the relative strength of coffee beverage in given amount of water, and requirements for packaging the ground coffee, while the degree of roasting is responsible for flavor and aroma as well as acrylamide formation $\stackrel{(12)}{2}$. Data on physical properties of green and roasted coffee are aplenty

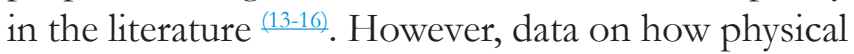
properties change during roasting especially when the beans are pre-treated prior to roasting are rare.

On the other hand, lot of researches have been carried out on texturing of natural products since 1988 when the Instant Controlled Pressure Drop Process (DIC) was developed for the first time. DIC is a controlled high temperature and short time process, it has been used successfully to improving the kinetics of some processes including drying, extraction and decontamination and to get better the function and organoliptic quality of some varieties of fresh and dried natural products. The main advantages of DIC over other existing technologies are that it is a master controlled temperature and time process, the dwell times are short, reducing the chemical degradation, so new products with superior quality attributes may be developed. The technology became available at the industrial level since 2004.

In previous work, we employed the DIC process as pre- treatment step prior to roasting, remarkable expansion characteristics were detected in the treated

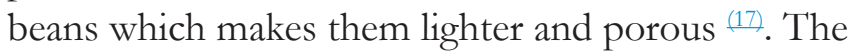
present work deals with modeling and optimization the roasting process for two types of coffee beans. The beans used are raw and pre-DIC treated Brazilian and Ethiopian commercial sources. 
The objective of this study is to highlight the effect of DIC treatment on the roasting characteristics of the roasted beans, in terms of density and roasting degree (as responses), as well as correlating the responses of the roasting process with the roasting processing conditions. The study also includes studying the kinetics of the roasting processes and evaluation the morphological characteristics of coffee beans using Scanning Electron Microscopy (SEM).

\section{MATERIALS AND METHOD}

\section{Materials}

The materials used are raw and DIC treated coffee beans of different variety (Brazilian and Ethiopian) commercial sources obtained from local markets. The beans from the 2 sources were treated by SteamDIC under identical processing conditions for comparison purposes. The processing conditions were: processing pressure $=5$ bar, processing time $=35$ sec. The initial water content $\%$ dry basis of coffee beans was determined by oven method following ISO 6673-1983 (E); green coffee determination of loss in mass at $105^{\circ} \mathrm{C}$ - Rapid method. The initial water content of the raw beans was: $7 \%$ and $11 \%$ for the Brazilian and the Ethiopian sources respectively. A preliminary moisturizing for the raw beans was conducted to achieve better expansion characteristics by the DIC process. The samples at increased moisture contents $(27 \%)$ were obtained by pre-soaking the raw beans in distilled water for predetermined time intervals. The samples were sealed well in polyethylene bags and stored at refrigerator at $5^{\circ} \mathrm{C}$.

\section{The Steam-DIC process}

The operation principle of the Steam-DIC process is composed of four sequential stages: 1. Preliminary Vacuum stage: For getting the greatest contact between steam and product surface. 2. Injection of steam: Establishing during ten seconds steam pressure for controlling the temperature of product $\left(\mathrm{T}<200{ }^{\circ} \mathrm{C}, \mathrm{P}<20\right.$ bars). 3. Pressure-Drop: Establishing an abrupt pressure drop ( $>>5$ bars.sec-1) towards vacuum, which implies auto-vaporization, cooling and a perfectly controlled "swelling" of the product. 4. Returning to atmospheric pressure. The Steam-DIC set-up is illustrated in Figure 1.

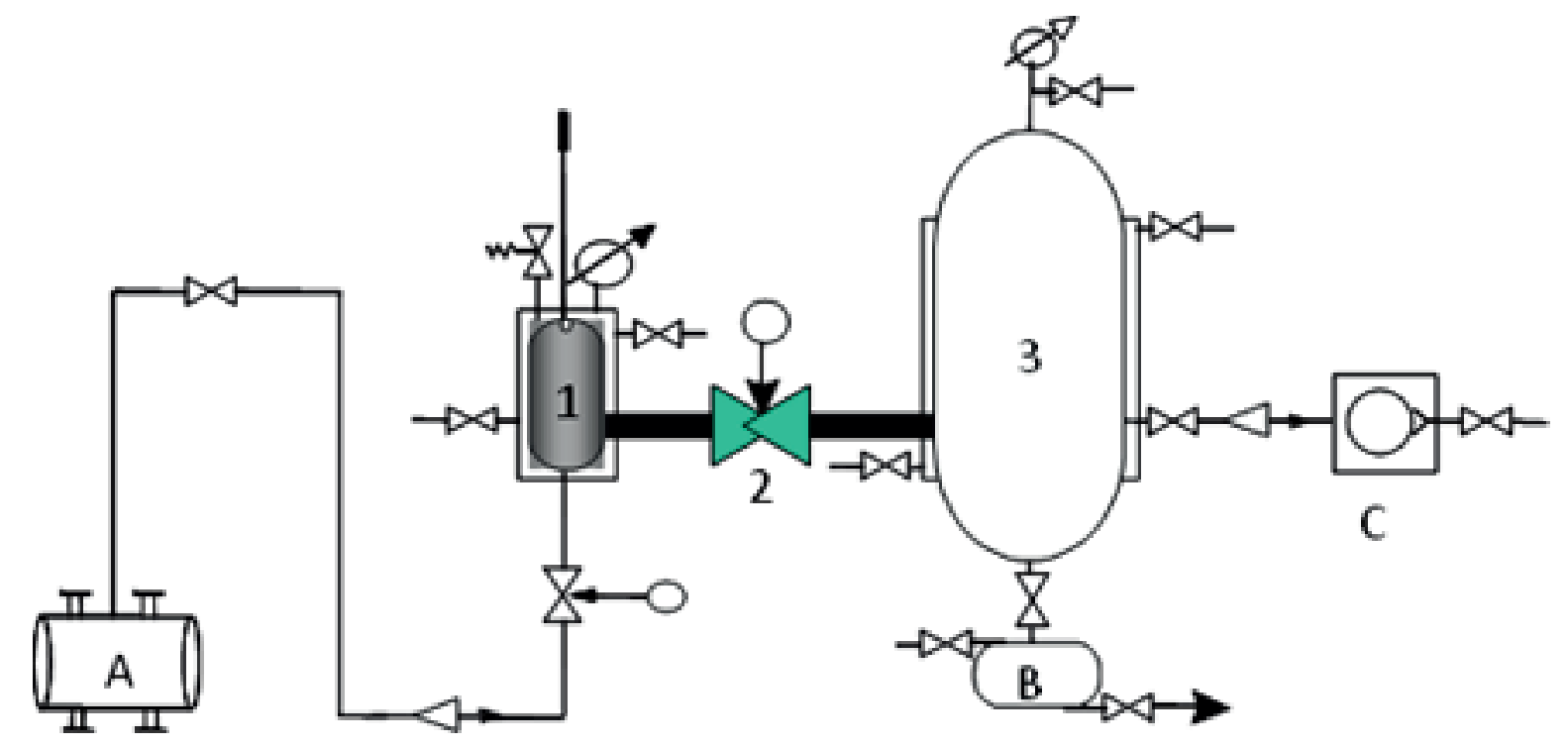

(1) : Reaction chamber. (2): Pressure Drop valve. (3): Vacuum tank. (A) : Steam generator. (B): condenser. (C): Vacuum pump.

Figure 1. The experimental set-up of the DIC process 


\section{Roasting process}

The roasting processes were performed using a laboratory air circulating oven ( Air Concept FirLABO AC 60, France ), at constant temperature (180, $190,215,240$, and $250{ }^{\circ} \mathrm{C}$ ) in order to simulate the roasting following an adopted experimental design. About $40 \mathrm{~g}$ of green coffee beans and DIC treated beans were placed on a stainless steel nets in a single layer. For each sampling step three nets were withdrawn from the oven and samples of beans were used for the analysis.

\section{Experimental design}

Mathematical and Statistical Methods are widely used for modeling and optimization in food processing. Several commercial and free statistical software are highlighted in literature in term of their advan-

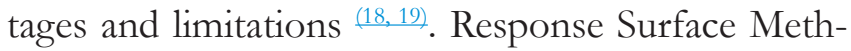
odology (RSM) using Statgraphics Plus for Windows software (5.1 version) for experimental design and data treatment was applied in the current work. The samples of roasted coffee were prepared according to a central composite design consisting of a 2 factorial with two levels $(-1,+1)$, four central points (0) and two levels of axial points $(-\alpha,+\alpha)$, resulting in 12 experiments. The independent variables being the roasting time and internal temperature of the roaster at the beginning of the roasting process. The times and temperatures varied, from 1 to $29 \mathrm{~min}$. and from 180 to $250{ }^{\circ} \mathrm{C}$ respectively. The dependent variables (responses) were: bulk density, solid density, normalized density and degree of roasting \%. The results were analyzed using Response Surface Methodology (RSM). For each experiment, the responses were evaluated and the data submitted to multivariate regression analysis, whose model contained linear, quadratic and interacting terms for the two independent variables. Adjusted models and their respective coefficients of determination were estimated.

\section{Responses determination \\ Density of coffee beans}

The bulk density of the roasted beans at various stages was determined as the ratio between beans mass and bulk volume. The solid density of the beans was determined by the water displacement method. An adopted pre-treatment step for the beans was carried out during this study by coating the beans with methyl cellulose thin edible film to avoid water absorption of the beans during the determination of solid density. Twenty-five beans of each sample were accurately weighed and dropped into $1000 \mathrm{ml}$ measuring cylinder filled with water up to $500 \mathrm{ml}$. The rise in water indicated the true volume of the beans. From the mass and the true volume of the beans, the true density was calculated. The normalized density was determined using the following relation:

Normalized density $=$ bulk density $(1+$ WT $/ 100) \ldots . .(1)$

Where WT is the weight loss due to the moisture/ dry matter during roasting $(2,11)$.

Degree of Roasting \%

Degree of roasting (\% dry weight loss of green coffee) was determined for the roasted beans using the following relation:

Degree of roasting $\%=(\mathrm{W} 2-\mathrm{W} 1 / \mathrm{W} 2) \times 100 \ldots .$.

Where: W1 is the final weight of the coffee beans after roasting, W2 is the initial weight of the coffee beans before roasting. The values of the responses factors correspond to averages of determinations or three replicates. 


\section{RESULTS}

The experimental results of the current work are demonstrated in Figures (2-13) and Tables (1-4).
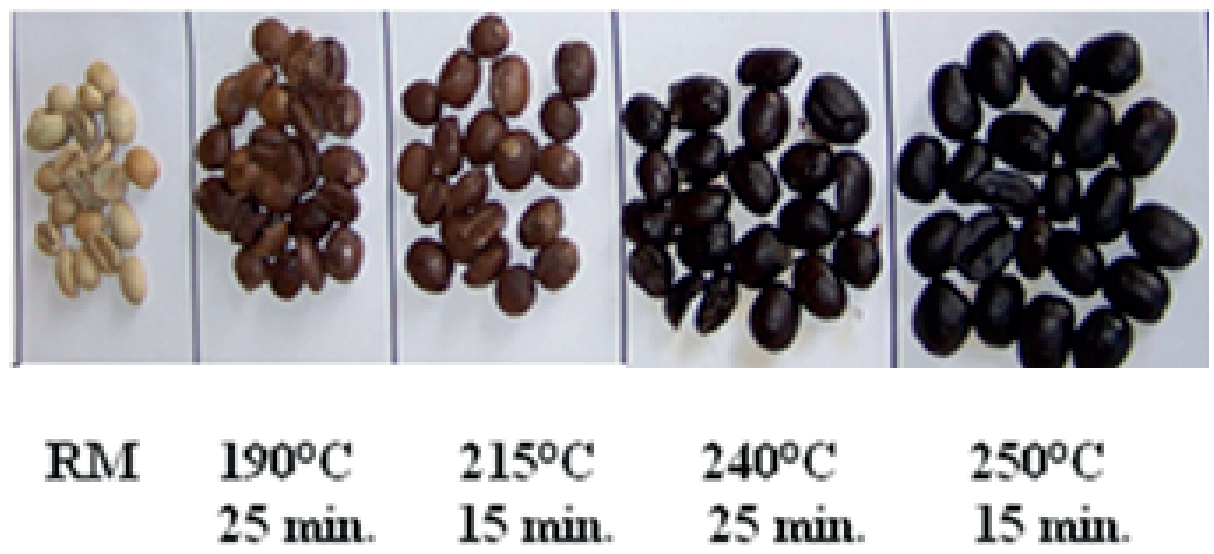

Figure 2. Samples of raw and DIC treated Ethiopian coffee beans and others roasted at different temperatures and times.

Table 1. Experimental design for the raw and the Steam-DIC treated and roasted Ethiopian coffee beans showing the coded, actual levels and the values of the responses.

\begin{tabular}{|c|c|c|c|c|c|c|c|c|c|c|}
\hline \multicolumn{3}{|c|}{ Experimental points } & \multicolumn{4}{|c|}{ Roasting Temp. $\left({ }^{\circ} \mathrm{C}\right)$} & \multicolumn{4}{|c|}{ Roasting Time (min.) } \\
\hline \multicolumn{3}{|c|}{ Point max. $(+\alpha)$} & \multicolumn{4}{|c|}{250} & \multicolumn{4}{|c|}{29} \\
\hline \multicolumn{3}{|c|}{ Point min. $(-\alpha)$} & \multicolumn{4}{|c|}{180} & \multicolumn{4}{|c|}{1} \\
\hline \multicolumn{3}{|c|}{ Point central } & \multicolumn{4}{|c|}{215} & \multicolumn{4}{|c|}{15} \\
\hline \multicolumn{3}{|c|}{ Point $(-1)$} & \multicolumn{4}{|c|}{190} & \multicolumn{4}{|c|}{5} \\
\hline \multicolumn{3}{|c|}{ Point (+1) } & \multicolumn{4}{|c|}{240} & \multicolumn{4}{|c|}{25} \\
\hline \multirow{2}{*}{\multicolumn{3}{|c|}{$\begin{array}{l}\text { Ethiopian CBs } \\
\text { experimental design }\end{array}$}} & \multicolumn{4}{|c|}{$\begin{array}{l}\text { Degree of } \\
\text { roasting }(\%)\end{array}$} & \multicolumn{3}{|c|}{ Density (kg/m3) } & \multirow{3}{*}{$\begin{array}{l}\mathrm{N} \\
\text { Control }\end{array}$} \\
\hline & & & & & $\mathrm{B}$ & B & S & S & $\mathrm{N}$ & \\
\hline $\begin{array}{l}\text { Exp. } \\
\text { No. }\end{array}$ & $\begin{array}{l}\text { Time } \\
\text { (min.) }\end{array}$ & $\begin{array}{l}\text { Temp. } \\
\left({ }^{\circ} \mathrm{C}\right)\end{array}$ & DIC & Control & DIC & Control & DIC & Control & DIC & \\
\hline 1 & 29 & 215 & 34.83 & 18.76 & 372 & 548 & 727 & 865 & 539 & 728 \\
\hline 2 & 25 & 240 & 51.03 & 36.60 & 346 & 370 & 720 & 853 & 477 & 624 \\
\hline 3 & 25 & 190 & 27.21 & 11.64 & 542 & 682 & 849 & 959 & 667 & 859 \\
\hline $4^{*}$ & 15 & 215 & 24.03 & 12.70 & 618.5 & 726 & 798.8 & 914.25 & 644 & 811.5 \\
\hline 8 & 15 & 180 & 16.49 & 5.91 & 705 & 744 & 853 & 883 & 732 & 833 \\
\hline 9 & 15 & 250 & 30.18 & 23.53 & 386 & 412 & 787 & 878 & 604 & 711 \\
\hline 10 & 5 & 240 & 12.78 & 5.00 & 672 & 728 & 905 & 923 & 802 & 879 \\
\hline 11 & 5 & 190 & 9.25 & 3.45 & 718 & 764 & 1023 & 1040 & 936 & 931 \\
\hline 12 & 1 & 215 & 11.20 & 1.42 & 692 & 740 & 960 & 1085 & 924 & 1070 \\
\hline \multicolumn{11}{|c|}{ B: Bulk density, S: Solid density, N: Normalized density } \\
\hline
\end{tabular}


Table 2. Experimental design for the raw and the Steam-DIC treated and roasted Brazilian coffee beans.

\begin{tabular}{|c|c|c|c|c|c|c|c|c|c|c|}
\hline \multirow{2}{*}{\multicolumn{3}{|c|}{$\begin{array}{c}\text { Brazilian CBs } \\
\text { Experimental Design }\end{array}$}} & \multirow{2}{*}{\multicolumn{2}{|c|}{$\begin{array}{c}\text { Degree of } \\
\text { Roasting }(\%)\end{array}$}} & \multicolumn{6}{|c|}{ Density $\left(\mathrm{kg} / \mathrm{m}^{3}\right)$} \\
\hline & & & & & \multirow{2}{*}{$\begin{array}{c}\text { B } \\
\text { DIC }\end{array}$} & \multirow{2}{*}{$\begin{array}{c}\text { B } \\
\text { Control }\end{array}$} & \multirow{2}{*}{$\begin{array}{c}\text { S } \\
\text { DIC }\end{array}$} & \multirow{2}{*}{$\begin{array}{c}\text { S } \\
\text { Control }\end{array}$} & \multirow{2}{*}{$\begin{array}{c}\mathrm{N} \\
\mathrm{DIC}\end{array}$} & \multirow{2}{*}{$\begin{array}{c}\mathrm{N} \\
\text { Control }\end{array}$} \\
\hline $\begin{array}{l}\text { Exp. } \\
\text { No. }\end{array}$ & $\begin{array}{l}\text { Time } \\
\text { (min.) }\end{array}$ & $\begin{array}{c}\text { Temp. } \\
\left({ }^{\circ} \mathrm{C}\right)\end{array}$ & DIC & Control & & & & & & \\
\hline 1 & 29 & 215 & 35.24 & 13.34 & 370 & 476 & 704 & 760 & 521 & 671 \\
\hline 2 & 25 & 240 & 37.8 & 26.91 & 358 & 438 & 675 & 714 & 490 & 562 \\
\hline 3 & 25 & 190 & 28.67 & 9.7 & 508 & 582 & 817 & 850 & 635 & 775 \\
\hline $4^{*}$ & 15 & 215 & 26.26 & 13.26 & 415 & 522 & 775.25 & 836 & 614.25 & 734.5 \\
\hline 8 & 15 & 180 & 19.14 & 6.62 & 554 & 602 & 866 & 960 & 727 & 900 \\
\hline 9 & 15 & 250 & 33.27 & 15.1 & 294 & 428 & 682 & 747 & 512 & 649 \\
\hline 10 & 5 & 240 & 11.75 & 4.78 & 490 & 572 & 885 & 913 & 792 & 872 \\
\hline 11 & 5 & 190 & 8.27 & 2.18 & 643 & 690 & 901 & 1156 & 832 & 1131 \\
\hline 12 & 1 & 215 & 3.89 & 0.67 & 676 & 706 & 966 & 1252 & 930 & 1243 \\
\hline
\end{tabular}

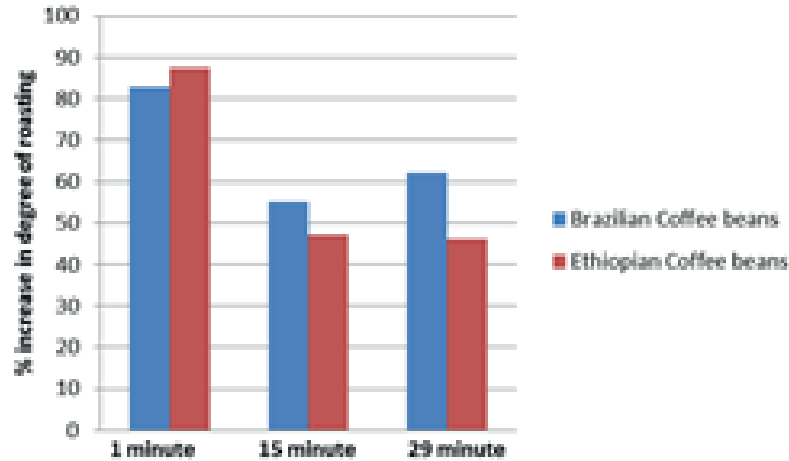

Figure 3. Percent increase in degree of roasting for DIC treated coffee beans roasted at $215^{\circ} \mathrm{C}$ for different time.

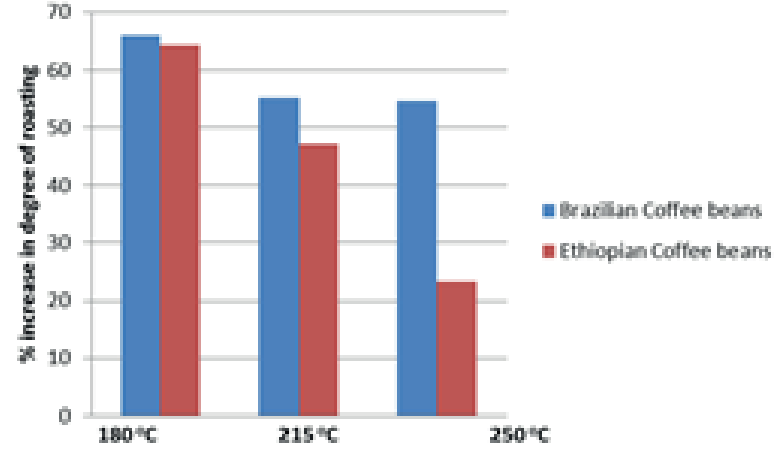

Figure 4. Percent increase in degree of roasing for DIC treated coffee beans for 15 min. at different temperatures.

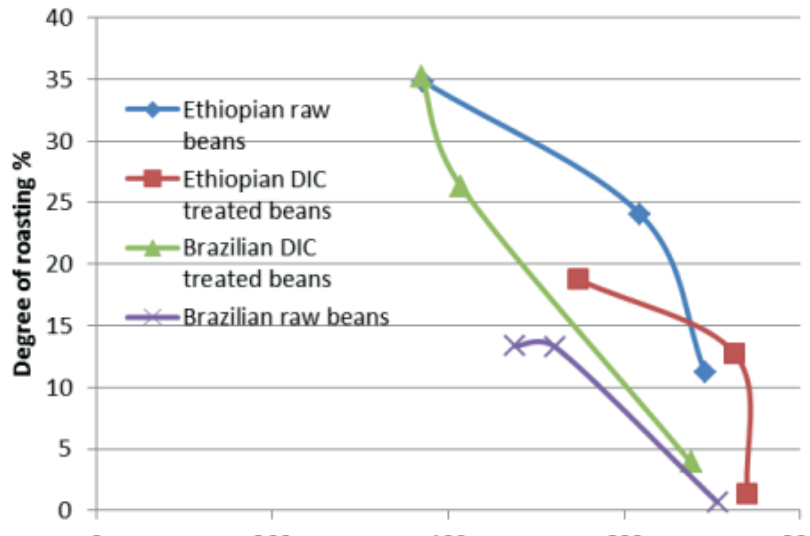

Figure 5. Variation of density with roasting degree of raw and DIC treated beans 

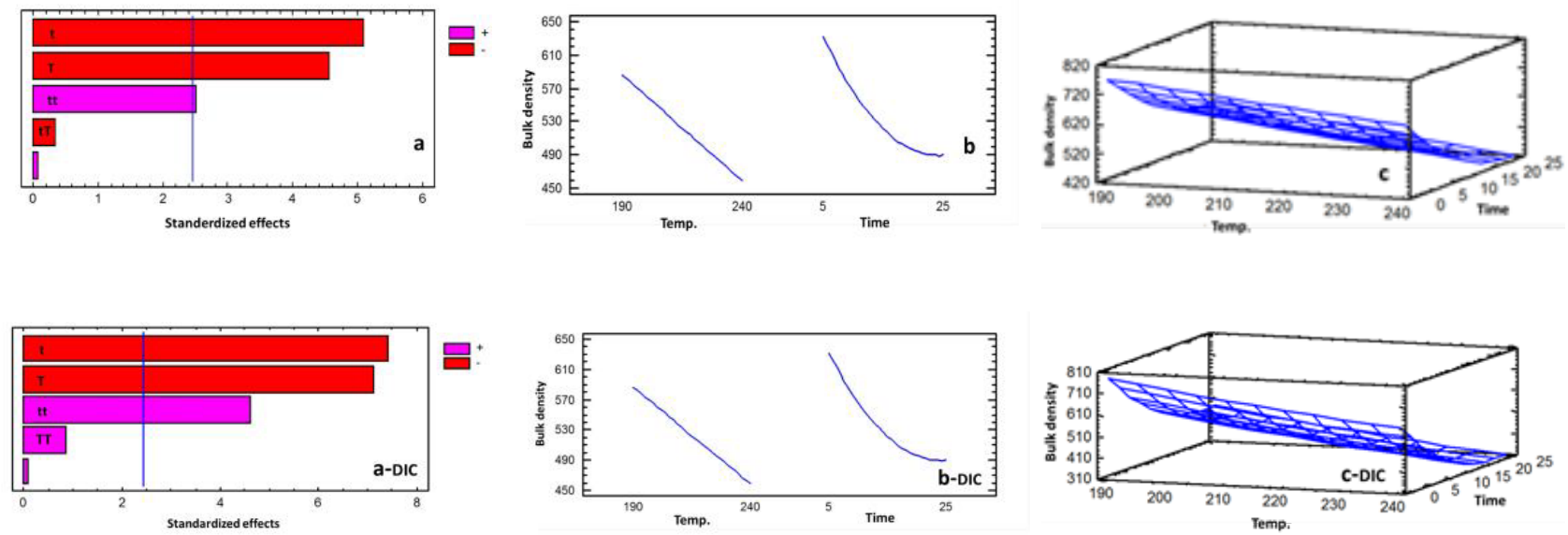

T: Roasting temperature, t: Roasting time

Figure 6. Response surfaces for bulk density of raw and DIC treated Brazilian coffee beans.
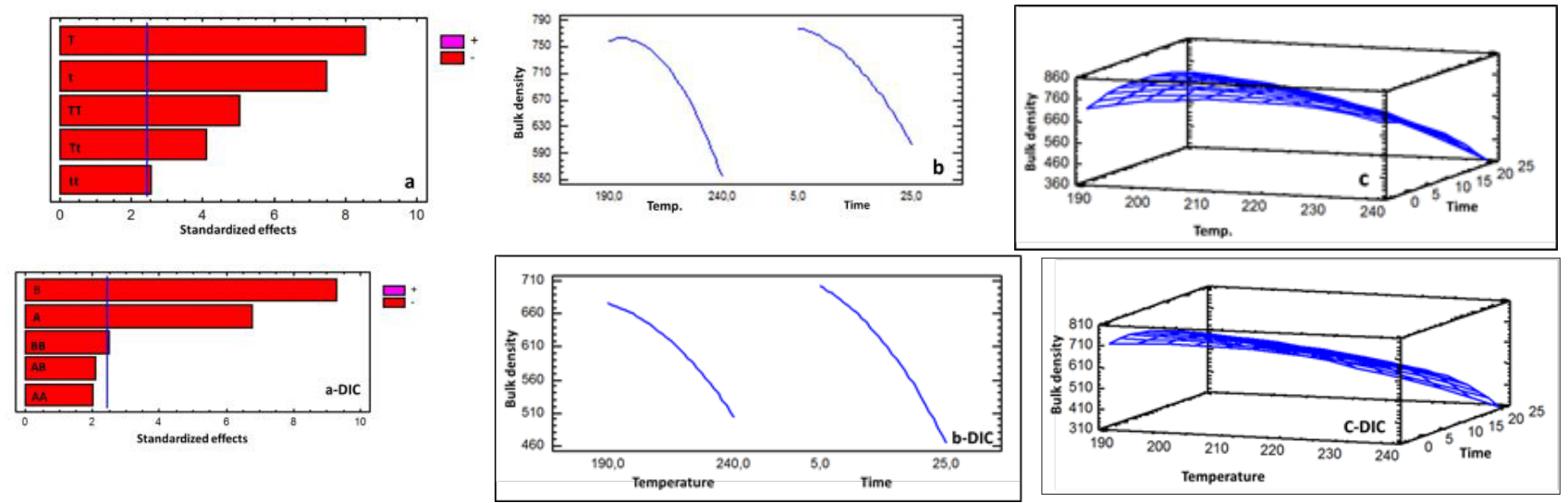

T or B: Roasting temperature, t or A: Roasting temperature

Figure 7. Response surfaces for bulk density of raw and DIC treated Ethiopian coffee beans.
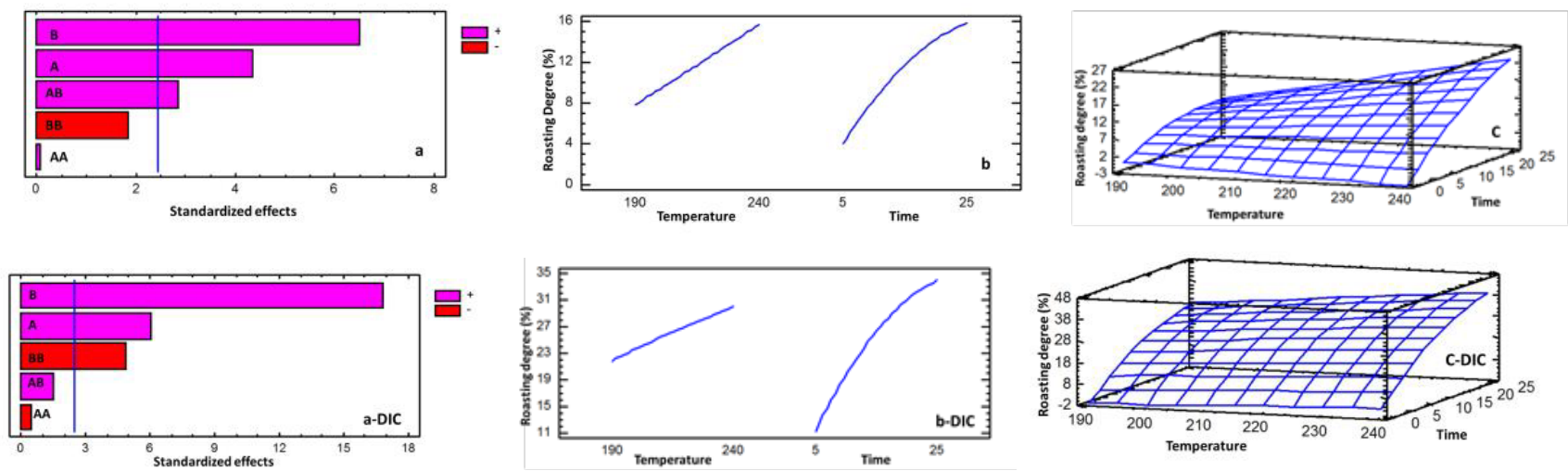

B: Roasting temperature, A: Roasting time

Figure 8. Response surfaces for roasting degree of raw and DIC treated Brazilian coffee beans. 

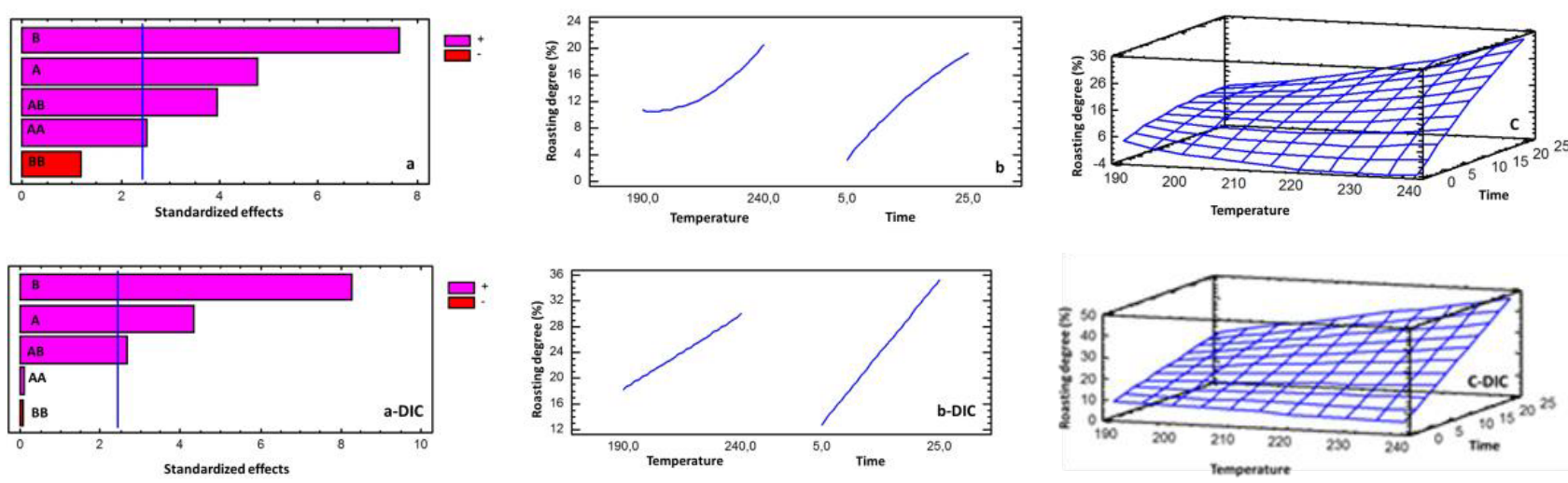

B: Roasting temperature, A: Roasting time

Figure 9. Response surfaces for roasting degree of raw and DIC treated Ethiopian coffee beans.

Table 3. Adjusted models from the physical responses of the roasted raw and steam-DIC treated coffee beans.

\begin{tabular}{llc}
\hline \multicolumn{1}{c}{ Responses } & \multicolumn{1}{c}{ Model } & $\mathbf{R}^{2}$ \\
\hline Bulk density (RB) $=$ & $1242.89-2.752 \mathrm{~T}-13.163 \mathrm{t}+0.0014 \mathrm{~T}^{2}-0.026 \mathrm{Tt}+0.389 \mathrm{t}^{2}$ & 89.84 \\
Bulk density (DIC B) $=$ & $2231.35-11.010 \mathrm{~T}-27.561 \mathrm{t}+0.0178 \mathrm{~T}^{2}+0.003 \mathrm{Tt}+0.606 \mathrm{t}^{2}$ & 95.44 \\
Bulk density (RE) $=$ & $-4157.4+45.891 \mathrm{~T}+60.533 \mathrm{t}-0.106 \mathrm{~T}^{2}-0.276 \mathrm{Tt}-0.336 \mathrm{t}^{2}$ & 96.33 \\
Bulk density (DIC E) & $-1152,15+18,607 \mathrm{~T}+30.987 \mathrm{t}-0.046 \mathrm{~T}^{2}-0.150 \mathrm{Tt}+0.356 \mathrm{t}^{2}$ & 96.01 \\
Solid density (RB) $=$ & $3150.65-12.746 \mathrm{~T}-64.265 \mathrm{t}+0.018 \mathrm{~T}^{2}+0.107 \mathrm{Tt}+0.875 \mathrm{t}^{2}$ & 95.69 \\
Solid density (DIC B) $=$ & $1249.87-2.351 \mathrm{~T}+8.696 \mathrm{t}+0.005 \mathrm{~T}^{2}-0.126 \mathrm{Tt}+0.336 \mathrm{t}^{2}$ & 97.13 \\
Solid density (RE) $=$ & $-1505.23+25.646 \mathrm{~T}-15.658 \mathrm{t}-0.063 \mathrm{~T}^{2}+0.011 \mathrm{Tt}+0.218 \mathrm{t}^{2}$ & 52.49 \\
Solid density (DIC E) $=$ & $-2904.18-16.157 \mathrm{~T}-16.141 \mathrm{t}+0.003 \mathrm{~T}^{2}-0.011 \mathrm{Tt}+0.33 \mathrm{t}^{2}$ & 89.03 \\
Normalized density (RB) $=$ & $3129.04-13.296 \mathrm{~T}-59.395 \mathrm{t}+0.02 \mathrm{~T}^{2}+0,046 \mathrm{Tt}+1.036 \mathrm{t}^{2}$ & 96.79 \\
Normalized density (DIC B) $=$ & $1630.72-5.213 \mathrm{~T}-8.686 \mathrm{t}+0.010 \mathrm{~T}^{2}-0.105 \mathrm{Tt}+0.593 \mathrm{t}^{2}$ & 98.44 \\
Normalized density (RE) $=$ & $-878.298+16.611 \mathrm{~T}-16.823 \mathrm{t}-0.034 \mathrm{~T}^{2}-0.182 \mathrm{Tt}+0.374 \mathrm{t}^{2}$ & 76.00 \\
Normalized density (DIC E) $=$ & $-2901.59-16.940 \mathrm{~T}-20.004 \mathrm{t}+0.037 \mathrm{~T}^{2}-0.056 \mathrm{Tt}+0.574 \mathrm{t}^{2}$ & 93.78 \\
Degree of Roasting \% (RB) $=$ & $-14.95-0,0920 \mathrm{~T}-1.982 \mathrm{t}+0.0001 \mathrm{~T}^{2}+0.015 \mathrm{Tt}-0.019 \mathrm{t}^{2}$ & 92.32 \\
Degree of roasting \% (DIC B) $=$ & $-41.11+0.313 \mathrm{~T}+1.019 \mathrm{t}-0.001 \mathrm{~T}^{2}+0.006 \mathrm{Tt}-0.037 \mathrm{t}^{2}$ & 98.28 \\
Degree of Roasting (RE) $=$ & $248.46-2.183 \mathrm{~T}-3.821 \mathrm{t}+0.005 \mathrm{~T}^{2}+0.0234 \mathrm{Tt}+0.014 \mathrm{t}^{2}$ & 94.6 \\
Degree of roasting (DIC E) $=$ & $31.85-0.159 \mathrm{~T}-3.23244 \mathrm{t}+0.0002 \mathrm{~T}^{2}+0.020 \mathrm{Tt}-0.0003 \mathrm{t}^{2}$ & 94.00 \\
\hline
\end{tabular}

RB: Raw coffee beans Brazilian, RE: Raw coffee beans Ethiopian, DIC B: DIC treated roasted coffee beans Brazilian, DIC E: DIC treated roasted coffee beans Ethiopian. 
Table 4. Roasting kinetics parameters for Brazilian and Ethiopian raw and Steam-DIC treated coffee beans

\begin{tabular}{ccccc}
\hline & \multicolumn{3}{c}{ Rate constant, $\mathrm{k}\left(\mathrm{min}^{-1}\right)$} \\
\cline { 2 - 6 } Roasting temperature & \multicolumn{2}{c}{$\begin{array}{c}\text { Ethiopian Coffee } \\
\text { beans }\end{array}$} & \multicolumn{2}{c}{$\begin{array}{c}\text { Brazilian Coffee } \\
\text { beans }\end{array}$} \\
\cline { 2 - 6 } & Raw & DIC & Raw & DIC \\
\hline $180^{\circ} \mathrm{C}$ & 0.0793 & 0.1573 & 0.0907 & 0.2287 \\
$190^{\circ} \mathrm{C}$ & 0.0855 & 0.1945 & 0.1005 & 0.2925 \\
$215^{\circ} \mathrm{C}$ & 0.1543 & 0.2368 & 0.1182 & 0.3410 \\
$240^{\circ} \mathrm{C}$ & 0.2450 & 0.334 & 0.2500 & 0.4485 \\
$\mathrm{R}^{2}$ & 0.9877 & 0.9781 & 0.8676 & 0.9577 \\
Activation Energy Ea $(\mathrm{kJ} / \mathrm{mol})$ & 37.98 & 22.75 & 30.72 & 19.85 \\
\hline
\end{tabular}
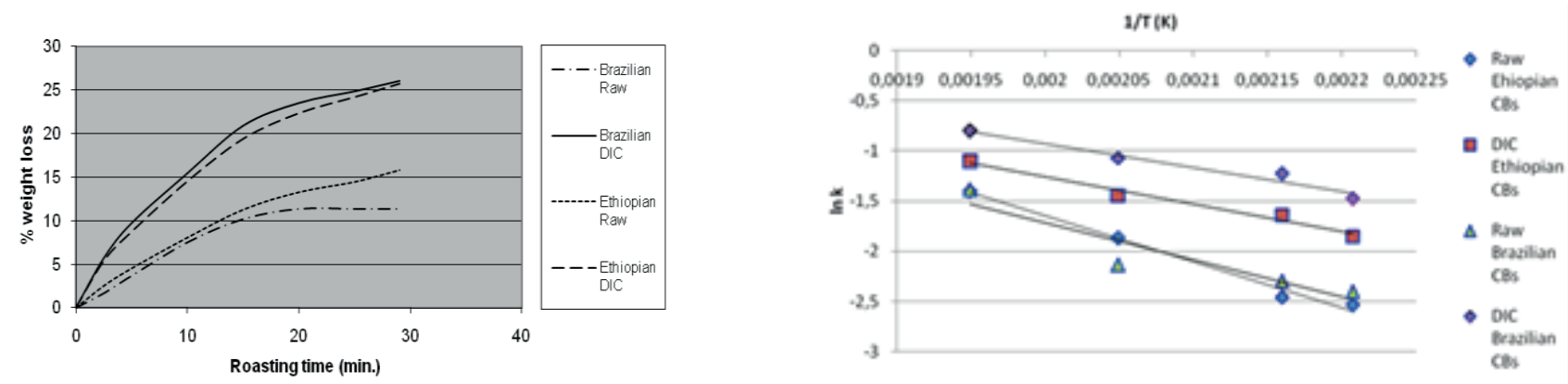

Figure 10. Typical roasting kinetics profile coffee beans and DIC treated coffee beans at $215^{\circ} \mathrm{C}$.

Figure 11. Arrhenius plot for the roasted raw for raw and DIC treated coffee beans
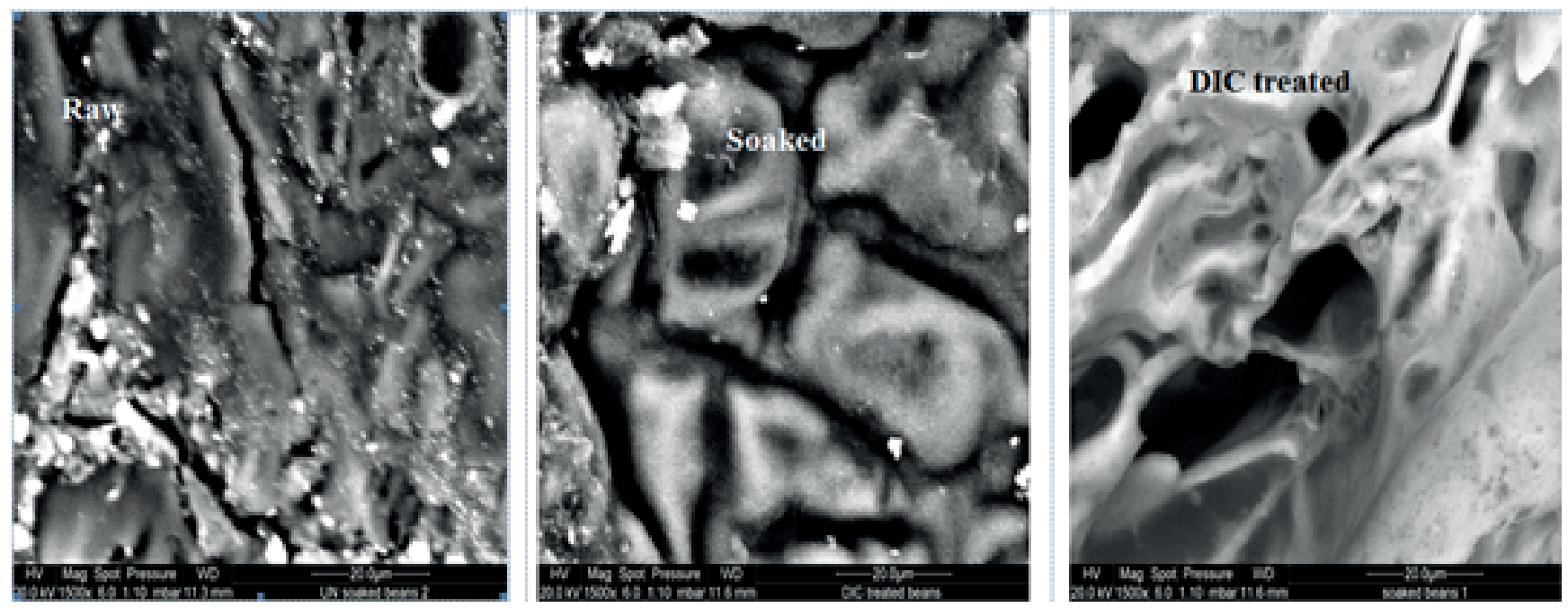

Figure 12 . Scanning electron microscopy images for raw, soaked and DIC treated Brazilian coffee beans. 

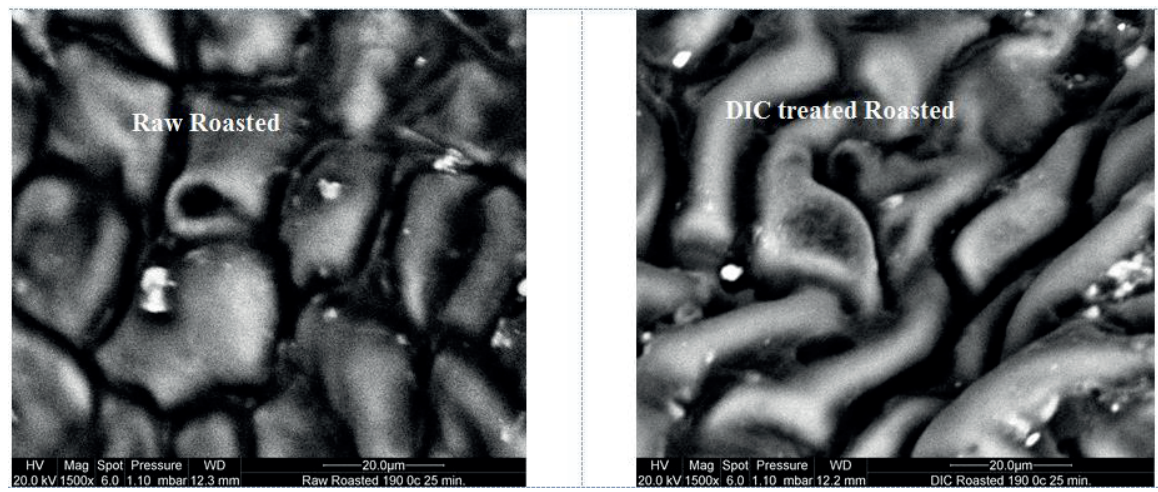

Figure 13. Scanning electrons microscopy images for raw roasted and DIC treated Brazilian coffee beans, roasted at $190^{\circ} \mathrm{C}$ for 25 minutes.

\section{DISCUSSION}

\section{Discussion the results of response surface anal-} ysis (RSA)

Roasting is the biggest factor in coffee beans quality. It leads to considerable changes in microstructure

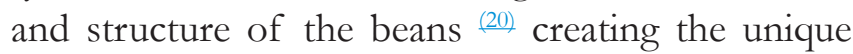
cup quality for coffee beverage. Raw and Steam-DIC treated beans of two varieties (Brazilian and Ethiopian), were roasted at temperature range from 180$250{ }^{\circ} \mathrm{C}$ for different time intervals ranging from 1-29 minute according a central composite experimental design. Figure 2 represents samples of the raw and roasted Ethiopian coffee beans treated by DIC prior to roasting. Response Surface Methodology RSM is an applicable method to optimize various processes in the field of food processing ${ }^{(21-23)}$. In the current work RSM was applied as a statistical analysis method for :(1) optimization the independent roasting variables (roasting time and temperature), (2) determination the lack of fit and the significance of the linear, quadratic and cross-products effects of the independent variables on some physical properties of roasted beans, and (3) investigation how physical properties change with changing roasting conditions for both the raw and DIC treated coffee beans. The process variables investigated during the roasting process as responses are density and roasting degree of the roasted beans.

Data of the central composite experimental design and the estimated values of the responses are summarized in tables 1 and 2 for Ethiopian and Brazilian sources coffee beans respectively. It is obvious from the experimental results that density values for the Steam-DIC treated samples are relatively lower compared to those of the raw beans for both the two varieties. The decrease in density during the roasting process may attribute to increase in bean volume results from softening and expansion of the cellulosic bean structure coupled to the increase in pressure from the release of pyrolysis products. The excess reduction in density of the DIC treated beans may be due to the additional expansion of the cellulosic bean structure created by the high temperature-short time DIC process prior to roasting $\stackrel{(17)}{\text {. }}$

During roasting the structural cell wall polymers are changing to a rubbery state allowing limited changing in volume but excessive changing in mass due to pyrolysis reactions. The degree of roasting for the DIC treated beans showed higher values compared to those of raw beans for both coffee varieties. There was a direct proportionality for degree of roasting with roasting time and temperature. However, the Brazilian source DIC treated coffee beans showed more increase in degree of roasting with increasing roasting time and temperature compared to the Ethiopian variety as shown in Figures 3 and 4.

The increase in degree of roasting with increasing roasting time and temperature is due to the decrease in mass of the beans. The primary loss of dry mass is due to escaping of carbon dioxide from the beans. Our findings are in agreement with those reported in the literature ${ }^{(6,24)}$. The higher roasting degree of the DIC treated beans compared to the untreated beans, may be owing to the excessive decrease in density for 
the DIC treated beans, and the more softening cellulosic structure, and weaker binding forces between the cellulose macromolecules. The variation of degree of roasting and bulk density for the raw and DIC treated Brazilian and Ethiopian coffee beans is shown in Figure 5. Degree of roasting decreases as density of the beans increases, however, the Brazilian Coffee beans showed sharper decrease compared to the Ethiopian variety. It is worthy to note that SteamDIC samples may achieve closer physical characteristics of the raw beans when roasted for lower times and at lower temperatures. This phenomenon confirms the efficacy of the Steam-DIC process prior to roasting and its contribution to conservation of time and energy besides the other improvements related to beans quality.

The response surface analysis data for the individual dependent variables for the raw and DIC treated samples represented in Figures 6-9. Each Figure composed of the Pareto chart of standardized effects, showed significant effects of all variables (linear and quadratic as well as of the interaction of the variables), quadratic plots and response surface plots which can be generated by holding constant one independent variable. A revised model was calculated for each of the responses, and representation of the responses was in terms of the polynomial quadratic equations containing six estimated coefficients with the coefficients of determination $\mathrm{R}^{2}$. The closer the value of $\mathrm{R}^{2}$ to unity, the better the empirical models fits the actual data. The lack of fit test is a measure of the failure of a model to represent data in the experimental domain at which points were not included in the regression. The adjusted models for the responses analyzed in this work tabulated in Table 3.

RSA was carried out for all the density descriptive values (bulk, solid, and normalized). Typical RSA for density shown in Figures 6 and 7, which represent the effect of roasting processing variables on bulk density for raw and DIC treated Brazilian and Ethiopian coffee beans respectively. The analysis of the overall data set of bulk density indicated that both roasting time and temperature have significant effects on bulk density. The more significance is relevant to roasting time rather than to roasting temperature, it showed more pronounced effect on bulk density. A significant quadratic and interaction effects between roasting time and temperature was observed but with less significance.

The maximum reduction in the value of bulk density observed when the roasting conditions were mostly 25 minutes at $240^{\circ} \mathrm{C}$ for the raw and DIC treated of the both varieties. However, the DIC treated beans lowered in bulk density compared to the raw beans. The lower bulk density values were (370, 438 and $\left.346,358 \mathrm{~kg} / \mathrm{m}^{3}\right)$ for the raw and DIC treated Ethiopian and Brazilian sources respectively.

The same trend observed for the response surface data relevant to solid density and normalized density. The lower values for the solid density were 853, 717 and $720,657 \mathrm{~kg} / \mathrm{m}^{3}$, while they were 642,562 and 477, 490 for the normalized density for the raw and DIC treated Ethiopian and Brazilian respectively. The overall reduction in the different forms of density was in the rage of (6-25) \% and (8-18) \% for the DIC treated Ethiopian and Brazilian coffee beans respectively compared to the raw untreated materials.

The statistical analysis results tabulated in table 3 indicated the satisfactory values of $\mathrm{R}^{2}$ for all the density responses. They ranged from 89.03 to 98.44 indicating that the most of the variation in the responses explained by the regression equations. Although, two regression coefficient values were less satisfactory, they were 76 and 52.49 related to the normalized and solid density for the raw Ethiopian coffee beans respectively. The lower significance effects of the roasting variables on the solid density and normalized density of the raw Ethiopian coffee beans, may be attributed to the lower quality of the beans containing higher defect beans compare to the higher quality, less defect content Brazilian coffee beans. The most pronounced significant effects of roasting conditions were observed for roasting degree (Figures 8 and 9). The effect of roasting time, roasting temperatures and also their composite were significant, also the quadratic representation and the surface response interactions were obvious and the estimated values of $\mathrm{R}^{2}$ were high: 92.32 , 94.6 and 98.28, 94 for the raw and DIC treated Brazilian and 
Ethiopian beans respectively. The results obtained confirmed that the relevant response surface models developed were adequate.

The highest degree of roasting obtained when coffee beans roasted for $25 \mathrm{~min}$. at $240{ }^{\circ} \mathrm{C}$ for the two coffee varieties. The estimated degree of roasting $\%$ were $(36.6,26.91$ and $51.05,37.8)$ for the raw and DIC treated Ethiopian and Brazilian coffee beans respectively. The $\%$ increase in roasting degree was 28.3 and 28.8 for the DIC treated Ethiopian and Brazilian coffee beans respectively compared to the untreated raw materials.

The noticeable increase in degree of roasting and decrease of densities for the DIC treated coffee beans could be attributed to the increase of the volume of the beans resulted from the expansion caused by the DIC texturing process, besides that resulted from the increase of the pressure of the internal gases, products $\left(\mathrm{CO}_{2}\right.$ and other thermal decomposition products) from the heat-induced roasting reactions. The overall results indicated that the DIC treated coffee beans can be roasted, achieving the required roasting degrees and the other physical characteristics using shorter times and lower temperatures compared to the raw beans.

\section{DISCUSSION THE RESULTS OF ROASTING KINETICS}

Coffee roasting is a time-temperature dependent process, whereby physical and chemical changes are induced to bring out flavor and aroma, with the degree of roasting depending on the temperature and duration of heating. Kinetics parameter such as reaction order, rate constant and activation energy, are very essential for predicting coffee quality loss during thermal processing $\stackrel{25,26)}{2}$, and storage conditions $\stackrel{(27)}{.}$ To the best of our knowledge, coffee roasting kinetics have not yet been investigated comprehensively, especially for those related to coffee pre-treated by thermo-mechanical processes prior to roasting.

In the current study, the kinetics data were estimated from roasting experiments which were conducted with three replications for raw and DIC treated coffee beans (Brazilian and Ethiopian). Forty g cof- fee samples (raw and DIC treated prior to roasting) were roasted by laboratory oven at 180, 190, 215 and $240{ }^{\circ} \mathrm{C}$ for $1-29 \mathrm{~min}$. The relations of $\%$ weight loss versus roasting time were plotted and the roasting rate constants were determined from the linear regression equations derived from the plots. A typical representative plot showing the weight loss curve for the raw and DIC Ethiopian treated beans is shown in Figure 10. It is obvious that the DIC treated coffee beans have much higher $\%$ weight loss across the roasting period compared to the raw materials with a magnitude relevant to coffee origin. The phenomena may be attributed to the texture expansion created by DIC process that facilitate the release of the volatiles at lower roasting time compared to that of raw materials.

From the plots, it is noticeable that the roasting process is a 2 - step process occurring at 2 rates. The representative behavior reflects two remarkable transitions with different slopes. The first transition proceeds with relatively higher rate compared to the later transition step. All the tested samples showed the same trend but with different rate magnitude. The DIC treated samples seemed having higher roasted rates for the two steps compared to the corresponding raw samples. The weight during the first stage is due to the release of water and other volatile compounds. The weight loss after that can be attributed to the release of the volatiles by-products and $\mathrm{CO}_{2}$ formed during pyrolysis reactions. The onset of pyrolysis can be associated with the transition between the 2 slops. This behavior has been reported by previous studies on coffee roasting $\stackrel{(28,29)}{\text {. Our }}$ results confirm that the raw samples transition occurred correspondently when about $10 \%$ weight loss is achieved, which is in agreement with the reviewed

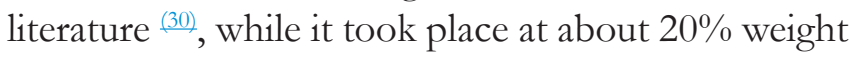
loss for the DIC treated samples. Our findings are so promising from economical point of view, by DIC pre-treatment similar roasting degrees of the raw can be achieved but with lower roasting time.

Some researchers demonstrated similar findings about the two roasting steps presenting two different rate ${ }^{(6)}$. Other researchers noted that the degradation of polysaccharides throughout the exother- 
mic phase of volatile generation during the second stage of roasting might be the rate-limiting step $\stackrel{(31)}{\text {. }}$ However, our findings are contrast in term of the increase in rate of the second roasting step. The reason may be attributed to the roasting technique. The critical operating parameters affecting coffee roasting are air speed distribution, temperature profile and duration $\stackrel{(32)}{-}$. When the roasting carried out in a roaster using relatively large quantity sample for example for example $1.5 \mathrm{~kg}$, the distribution of the heat through the multilayer sample at the beginning of the roasting process is not uniform, as the outer layers are totally exposed to the heat, whilst the inner layer exposed partially, therefore the first transition step proceeds with lower rate compared to the second transition step that proceed at higher rate, as more chance is available to heat and mass transfer throughout the pyrolysis reactions take place in the second step, while we carried out our roasting experiments using laboratory oven and monolayer, small quantity samples.

The dependence of the roasting rate constant on temperature was quantified by the Arrhenius equation:

$\mathrm{k}=\mathrm{A}^{\circ} \exp (-\mathrm{Ea} / \mathrm{RT})$

Where $\mathrm{Ea}$ is the activation energy of the reaction $(\mathrm{kJ} / \mathrm{mole}), \mathrm{R}$ the universal gas constant ( $8.3145 \mathrm{~J}$ mole $/ \mathrm{K}$, $\mathrm{T}$ the absolute temperature $(\mathrm{K})$ and $\mathrm{A}^{\circ}$ the frequency factor $\left(\mathrm{min}^{-1}\right)$ is a pre-exponential constant.

Data on the roasting parameters and the derived parameters of roasting kinetics are shown in table 4 . The corresponding Arrhenius plot is illustrated in Figure 11.

For all the samples analyzed, a correlation coefficient $>0.87$ was obtained suggest that the roasting reactions follow first order reaction. The linear nature of the plots obtained indicates that the roasting process conforms to the Arrhenius equation. The DIC treated samples seemed to have lower activation energy compared to the raw materials. About 35\% and 40\% reduction in activation energy was achieved for the
DIC treated Brazilian and Ethiopian coffee beans respectively. However, higher activation energy values $(52.27 \mathrm{~kJ} /$ mole) were reported to start the mass loss for a commercial Arabica coffee beans processed in continuous roaster with firing gas $\stackrel{(33)}{\text {. }}$

From Figures 10 and 11, it is obvious that the DIC treated beans were roasted at higher roasting rates and with higher loss in weight compared to the raw beans. Besides, there is no significant difference in the magnitude of weight loss $\%$ between the raw varieties and also between the DIC treated ones especially during the first roasting step. The results obtained confirms that the roasting kinetics change with changing coffee origin and are highly dependent on the texture nature of the beans.

\section{DISCUSSION THE RESULTS OF SCAN- NING ELECTRON MICROSCOPY ANALY- SIS}

It is well known that materials properties depend on the material microstructure, which in turn results from its composition and processing. SEM has long been widely used as surface imaging and analysis tool for education, research and industry. The fast advancements in nano-technology, human genomic research and biotechnology demand sophisticated electron optics that can provide sub-nanometer for even sub-angstrom imaging capabilities.

In order to observe the micro-structure of the roasted and unroasted raw and DIC treated coffee beans, Scanning Electron Microscope (SEM) was used for the purpose. The raw, soaked, and DIC treated, as well as the raw and DIC treated Brazilian coffee beans roasted at $190^{\circ} \mathrm{C}$ for 250 minute were observed as sections made along the transverse axis by dry-fracturing. Samples were mounted on aluminium stubs. Their ultra-structure was imaged in the scanning electron microscope (SEM) (Philips Quanta 200ESEM/FEG) under high vacuum $(1,1 \mathrm{mbar})$ at an accelerating voltage of $20 \mathrm{kV}$.

The images obtained are represented in Figures 12 and 13. Figure 12 shows the images for each of raw, soaked and DIC treated Brazilian coffee beans with 
magnifications (1500x). Figure 13 shows two images for roasted raw and DIC treated coffee beans with the same magnification taking into consideration that the dark regions in the images refer to cavities or pores. The results concluded from the texture microscopic analysis illustrated in Figure 12, reveal that micro structure of the raw coffee beans seemed to be relatively, highly homogeneous, well compacted and with high solid content. With the magnification used, we can see very dense texture included some well-defined narrow longitudinal cavities.

The feature dominated of the soaked beans micro structure compared to the raw beans structure is a less compacted swelled structure formed by absorption of water during the soaking process leads to softening the cellulose cells of the beans. We can observe that the structure is characterized by swelled thick outer skin as channels surrounding solid fragments. However, the fragmented solid content of the structure was still joined and not separated.

The DIC treated coffee beans micro structure seemed to be less compacted and with less solid content. With the higher magnification, we can notice the presence of pores with wide size distribution ranging from about $(6.5$ to $30 \mu \mathrm{m})$. The expanded micro structure could be defined obviously. The expansion may be attributed to the vaporization of the water from the beans micro-structure by the instantaneous abrupt pressure drop during the DIC process. The furrows and corrugations of the structure are well defined and the regularity and homogeneity of the shape of the solid fragments compared to those for the soaked beans is noticeable. The overall texture is characterized by remarkable large surface area.

Different observations derived from Figure 13 for the roasted raw and DIC treated coffee beans. The images reflect a texture which obviously refers that the roasting accomplished with a noticeable expansion in the structure of the beans due to the loss of water and some other volatile components naturally formed as roasting products. Moreover, the roasted raw beans seemed to have less homogenous surface structure compared to the DIC treated beans prior to roasting. Images for the roasted raw coffee beans shows surface structure composed of well-defined solid fragments having a puffed shape. The roasted Steam-DIC treated coffee beans surface structure is characterized by uniform distribution of solid fragments with different shape compared to the micro-structure of the roasted raw beans. The solid fragmented features seemed to have longitudinal shape with a larger surface area. The situation is an evident for the extra regular and controlled expansion of the bean's texture taken place prior to the roasting process.

\section{CONCLUSIONS}

The conclusions drawn from the current work are summarized as the following:

1. Physical properties of roasted coffee beans are highly affected and changed with coffee origin, roasting conditions and pre-treatment of coffee beans prior to roasting using the thermo-mechanical Instant Controlled Pressure Drop process (DIC).

2. The incorporation of DIC process prior to roasting seemed to achieve more conservation of time and energy needed for roasting compared to the raw untreated beans (cost effective).

3. The higher roasting degree and the competitive roasting activation energy of the Brazilian coffee beans compared to the Ethiopian give a conclusion that more economic roasting process could be achieved with the Brazilian variety.

4. Pre- treatment by DIC technology enhances remarkable reduction in coffee beans density, and increasing in roasting degree that are in line with the industrial needs of coffee beverage.

5. Response Surface Methodology is an efficient tool for optimization and mathematical modelling of coffee roasting process. 


\section{REFERENCES}

1. Oosterveld A, Voragen J, Schols A. Effect of roasting on the carbohydrate composition of coffee arabica beans. Carbohyd Polym. 2003. 54: 183-192.

https://doi.org/10.1016/S0144-8617(03)00164-4

2. Redgwell J, Trovato V, Curti D, Fischer M. Effect of roasting on degradation and structural features of polysaccharides in Arabica coffee beans. Carbohyd Res. 2002; 337: 421-431. https://doi.org/10.1016/S0008-6215(02)00010-1

3. Flament I. Coffee Flavor Chemistry (Ch. 3.), New York: John Wiley and sons, LTD; 2002.

4. Nursten H. The Maillard Reaction. Chemistry, Biochemistry, and Implications. RSC: Cambridge, UK; 2005.

5. Lyman J, Benck R, Dell S, Merle S, and Murray-Wijelaths J. FTIR-ATR Analysis of Brewed Coffee: Effect of Roasting Conditions. J. Agric. Food Chem. 2003; 51: 3268-3272. https://doi.org/10.1021/jf0209793

6. Rodrigues A, Borges A, Franca S, Oliveria S , Correa C. Evaluation of physical properties of coffee during roasting. Ag. Eng. Int.: The CIGR J Sci Res Dev Presented at the ASAE annual International meeting/CIGR XVth World congress. Chicago, II. 2002. Manuscript FP 03 004. Vol. December; 2003.

7. Paur I, Balstad R, Blomhoff R. Degree of roasting $s$ the main determinant of the effects of coffee on NF- $x$ B and EpRE. Free Radic. Biol. Med 2010; 48: 1218-1227.

https://doi.org/10.1016/j.freeradbiomed.2010.02.005

8. Hashim L, Chaveron H. Use of methyl pyrazine ratios to monitor the coffee roasting. Food Res Int 1996; 28: 619-623. https://doi.org/10.1016/0963-9969(95)00037-2

9. Farah A, Monteiro C, Calade V, Franca S, Trugo C. Correlation between cup quality and chemical attributes of Brazilian coffee. Food Chem. 2006; $98: 373-380$.

https://doi.org/10.1016/i.foodchem.2005.07.032

10. Uman E, Colonna-Dashwood M, Colonna-Dashwood L, Perger M, Klatt C, Leighton S, Miller B, Butler K, Melot B, Speirs R \& Hendon C . The effect of bean origin and temperature on grinding roasted coffee. Scientific Reports 2016; 6: Article number: 24483. https://www.nature.com/articles/srep24483.

https://doi.org/10.1038/srep24483

11.Chandrasekar V, Viswanathan R. Physical and thermal properties of coffee. J. Agric. Engng. Res. 1999; 73: 227-234.

https://doi.org/10.1006/jaer.1999.0411

12. Alves C, Soares C, Casal S, Fernandes O, Beatriz M, Oliveira P. Acrylamide in espresso coffee: Influence of species, roast degree and brew length. Food Chem 2010; 119: 929-934.

https://doi.org/10.1016/j.foodchem.2009.07.051

13. Ghosh N. Physical properties of different grades of arabica beans. Transactions of the ASAE. 1996; 9(3): 592-593.

14. Jokanovića M, Džinića N, Cvetkovićb B, Grujićc $\mathrm{S}$ and Odžaković B. Changes of physical properties of coffee beans during roasting. APTEFF 2012; 43:1-342.

https://doi.org/10.2298/APT1243021J

15. Schenker S, Handschin S, Frey B, Perren R and Escher F. Structural properties of coffee beans as influenced by roasting conditions. Association Scientifique Internationale du Cafe 18th Symposium: Helsinki, Finland; 1999.

16. Edzuan, A, Noor Aliah A, Bong H. Physical and Chemical Property Changes of Coffee Beans during Roasting. Am. J. Chem. 2015; 5(3A): 5660.

17. Kamal I, Sobolik V, Kristiwan M, Mounir S, Allaf K. Structure expansion of Green Coffee Beans Using Instantaneous Controlled Pressure Drop Process. J IFSET 2008; 9: 534-541.

https://doi.org/10.1016/j.ifset.2008.01.004

18. Nunes C, Alvarenga V, SantAna A, Santos J, Granato D. The use of statistical software in food science and technology: Advantages, limitations and misuses. J Food Res Int. 2015; 75: 270-280.

https://doi.org/10.1016/i.foodres.2015.06.011

19.Granato D, Ares G. Mathematical and Statistical Methods in Food Science and Technology: John Wiley \& Sons, Ltd; 2014.

https://doi.org/10.1002/9781118434635

20.Pittia P, Rosa M, Lerici C. Textural changes of coffee beans as affected by roasting conditions. Lebensm-Wiss. U- Technol 2001; 34: 168-157. https://doi.org/10.1006/fstl.2000.0749 
21.Luciane C, Hilary C, Aparecida M, and Silva A . Optimisation of roasting of Robusta coffee ( C. canephora conillon)using acceptability tests and RSM 2001; 2: 153-162.

https://doi.org/10.1016/S0950-3293(00)00042-2

22. Tsapatsaris $S$ and Kotzekidou. Application of central composite design and response surface methodology to the fermintation of olive juice by Lactobacillus plantarum and Debaryomyces hansenii. Intern. J Food Bio.2004; 95: 157-168.

https://doi.org/10.1016/j.ijfoodmicro.2004.02.011

23. Lee W, Yousof S, Hamid N, Baharin B. Optimizing conditions for hot water extraction of banana juice using response surface methodology (RSM). J Food Eng 2006; 75: 473-479.

https://doi.org/10.1016/j.jfoodeng.2005.04.062

24. Alessandrini L, Romani S, Pinnavaia G, Rosa M.

Near infrared spectroscopy: An analytical tool to predict coffee roasting degree. Analytica Chimica Acta. 2008; 625: 95-102. https://doi.org/10.1016/i.aca.2008.07.013

25. Medoua G, Mbofung C. Kinetics studies of some physico-chemical substances during roasting and preparation of beverage made by Cassia occidentalis seeds. LWT-Food Sci Technol 2007; 40: 730736. https://doi.org/10.1016/j.lwt.2006.03.004

26.Vargas-Elías G, Correa P, de souza R, Melo E. Kinetics of mass loss of arabica coffee during roasting process. Engenharia Agricola 2016; 36(2): 300-308.

https://doi.org/10.1590/1809-4430-Eng.Agric. v36n2p300-308/2016

27.Tsai S-Y, Hwang B-F, Wang S-P, Lin C-P. A Kinetics Study of Coffee Bean of Roasting and Storage Conditions. J Food Process Pres 2017; 41(4).https:// onlinelibrary.wiley.com/doi/ abs/10.1111/jfpp.13040.

https://doi.org/10.1111/ifpp.13040

28. Oliveira S, Franca A, Gloria M, and Borges M. The effect of roasting on the presence of bioactive amines in coffee of $\mathrm{f}$ different qualities. Food Chemistry. 2005; 90: 287-291.

https://doi.org/10.1016/j.foodchem.2004.03.056

29. Franca A, Oliveira L, Oliveira R, Agresti P, Augusti R. A preliminary evaluation of the effect of processing temperature on coffee processing degree assessment.. J Food Process Eng 2009; 92: 345-352.

https://doi.org/10.1016/j.jfoodeng.2008.12.012
30.Sivetz M and Desrosier N. Coffee Technology. Westport, Co: Avia Publishing Co.; 1979.

31.Wang X. Understanding the Formation of $\mathrm{CO}_{2}$ and Its Degassing Behaviours in Coffee. $\mathrm{PhD}$ Thesis, University of Guelph, Ontario, Canada; 2014.

32.Chiang C-C, Wu D-Y, Kang D-Y. Detailed Simulation of Fluid Dynamics and Heat Transfer in Coffee Bean Roaster. J Food Process Eng 2017; 40(2). https://onlinelibrary.wiley.com/doi/ abs/10.1111/jfpe.12398. https://doi.org/10.1111/ifpe.12398

33. Vargas-Elías G, Corrêa P, De souza N, Baptestini F, Melo E. Kinetics of mass loss of arabica coffee during roasting process. J. Braz. Ass. Agr. Eng 2016; 36(2): 300-308.

https://doi.org/10.1590/1809-4430-Eng.Agric. v36n2p300-308/2016 